\title{
Judgments of women wearing eyeglasses: a focus on specific dimensions of physical attractiveness
}

\author{
Yasuto Okamura ${ }^{1}$ \\ ${ }^{1}$ Graduate School of Psychology, Otemon Gakuin University, Osaka, Japan.
}

Received 26.02.2018; Received revised 17.05.2018; Accepted 06.06.2018

Available online 30.06.2018

\begin{abstract}
Several studies have examined how our judgment of another's physical attractiveness is affected when the other person is wearing eyeglasses. The present study identified various factors related to physical attractiveness and examined the eyeglasses effect for each of these factors. In the study, male and female participants viewed two photographs of the same woman's body profile. In one photograph, the woman wore eyeglasses; in the other, she did not. Participants were asked to select one of the photographs based on various dimensions of physical attractiveness. Results showed that the woman wearing no eyeglasses was judged to be prettier and better-looking, and that her photograph would be preferred by others and be preferable for inclusion in an album. On the other hand, the woman wearing eyeglasses was judged to be more elegant. These findings support the assumption that the eyeglasses effect differs for different dimensions of physical attractiveness.
\end{abstract}

Keywords: eyeglasses, attractiveness, women.

Address of correspondence: Yasuto Okamura, Graduate School of Psychology, Otemon Gakuin University, 2-1-15 Nishiai, Ibaraki City, Osaka 567-8502 Japan.

E-mail: yasu0night.person@gmail.com

\section{Introduction}

Facial accessories, such as piercings (Swami et al., 2012), female cosmetics (Mulhern, Fieldman, Hussey, Lévêque, \& Pineau, 2003), and sanitary masks (Miyazaki \& Kawahara, 2016) can influence facial impressions and features. In fact, facial impressions are judged extremely quickly. It has been shown that a relatively brief exposure to a face is all that is needed to make specific trait inferences. For example, we make quick judgments about another's threating personality (Bar, Neta, \& Linz, 2006), competence, trustworthiness, likeability, and attractiveness (Willis \& Todorov, 2006). We focus on eyeglasses, which are currently used not only for correcting eyesight but also as fashion items. Eyeglasses can also change one's impression of the wearer's face.

The first psychological study that investigated the effect of eyeglasses on person perception reported that individuals photographed wearing eyeglasses were scored higher for trustworthiness, diligence, intelligence, and honesty than when they were photographed without eyeglasses (Thornton, 1943). In recent studies, Guéguen (2015) and Okamura (2018) showed that people who wear eyeglasses are likely to be judged as belonging to intellectual occupations. Children in early infancy also already associate eyeglasses with intelligence despite the research that shows their mostly negative stereotypes of eyeglasses (Jellesma, 2013).

As seen above, there is consistent evidence that eyeglasses could increase the perceived intelligence of wearers. By contrast, the effect of eyeglasses on perceived physical attractiveness is not consistent. Several studies reported that eyeglasses made the wearer's appearance less attractive (e.g., Hasart \& Hutchinson, 1993; Leder, Forster, \& Gerger, 2011; Lundberg \& Sheehan, 1994; Terry \& Kroger, 1976). On the other hand, some researchers have found that eyeglasses have no effect on physical attractiveness (e.g., Brown, Henriquez, \& Groscup, 2008; Lo et al., 2012). A possible explanation for this inconsistency in the various studies reporting on the effect of eyeglasses on our judgment of physical attractiveness might be that physical attractiveness consists of multiple factors. In one study, for example, it has been measured on five dimensions: sexy, elegant, beautiful, classy, and attractive (Yoo \& Jin, 2015). Another study proposed that physical attractiveness consists of four different dimensions: the sexy-beauty attraction, the young-healthy attraction, the slim-body style attraction, and the whitesanitary attraction (Kawana, 2013). It would seem that additional research is needed to clarify which particular 
aspects of physical attractiveness are influenced by the wearing of eyeglasses.

This exploratory study uses a forced-choice evaluation task to investigate the effect of eyeglasses on some of the key dimensions of physical attractiveness.

\section{Method}

\section{Participants}

Participants were 55 men and 56 women (aged between 18 and 26 years). Sample sizes were calculated using G*Power 3.1.9.2 (Faul, Erdfelder, Lang, \& Buchner, 2007) and the parameters alpha $=0.05$ and power $=0.8$. They received a questionnaire and responded to it. They were informed that they could drop out of the study at any time during the survey and their informed consent was obtained before taking part in the study.

\section{Stimuli}

Two photographs of the same 23-year-old Japanese woman were used as targets in this study. They were printed in black and white on a white sheet of paper. The female target was either wearing or not wearing eyeglasses. The eyeglasses had been added to the facial image using software for fitting simulation of eyeglasses in order to maintain exactly the same facial expressions. The target was shown facing the front with a pleasant smile on her face. In a pilot test with a separate sample of 8 men and 7 women (aged between 18 and 25 years), this female received a mean attractiveness rating of $4.07(S D=1.12)$ on a scale ranging from 1 (not at all attractive) to 7 (extremely attractive).

\section{Procedure}

Participants were given a sheet of paper with the two photographs printed on the top half of the sheet. One of the photographs was labelled "A"; the other was labelled "B." The arrangement order of the photographs was counterbalanced and the presentation order of the seven items was randomized by presenting the materials in a block-wise manner. On the bottom half of the sheet, there were several questions associated with the evaluation of the target's physical appearance: sexiness, prettiness, elegance, good-looking, and youth. Two questions were added regarding which photograph would be preferred by other individuals, and which photograph the participant would choose for a photo album. These two questions were based on Guéguen, Stefan, and Renault (2016). Participants were instructed to indicate which of the women in the photographs was sexier, prettier, and so on, for each dimension. Three responses were offered: A, B, or "no difference." This forced-choice evaluation was based on each participant's subjective judgment of which the woman looks more attractive.

\section{Results}

Participants' target choices by gender are shown in Table 1. An independent chi-square test showed that the woman wearing no eyeglasses was judged to be prettier (Male: $\chi^{2}(2)=6.26, p<.05$, Female: $\chi^{2}(2)=19.00, p<$ .001 ) and better-looking (Male: $\chi^{2}(2)=29.49, p<.001$, Female: $\left.\chi^{2}(2)=33.89, p<.001\right)$, and that her photograph would be preferred by others (Male: $\chi^{2}(2)=7.13, p<.05$, Female: $\left.\chi^{2}(2)=36.46, p<.001\right)$ and for an album (Male: $\chi^{2}(2)=48.04, p<.001$, Female: $\left.\chi^{2}(2)=56.39, p<.001\right)$. On the other hand, the woman wearing eyeglasses was judged to be more elegant (Male: $\chi^{2}(2)=11.82, p<.01$, Female: $\left.\chi^{2}(2)=23.61, p<.001\right)$. Sexiness (Male: $\chi^{2}(2)=$ $31.89, p<.001$, Female: $\left.\chi^{2}(2)=12.89, p<.01\right)$ and youth (Male: $\chi^{2}(2)=62.66, p<.001$, Female: $\chi^{2}(2)=32.71, p<$ $.001)$ were not influenced by the presence of eyeglasses. Results showed no gender difference in participant responses in all items (Sexiness: $\chi^{2}(2)=2.23, p=.33$, Prettiness: $\chi^{2}(2)=1.52, p=.47$, Elegance: $\chi^{2}(2)=1.38, p$ $=.50$, Good-looking: $\chi^{2}(2)=3.51, p=.17$, Youth: $\chi^{2}(2)=$ 5.02, $p=.08$, Selected by others: $\chi^{2}(2)=2.20, p=.33$, Selected for an album: $\left.\chi^{2}(2)=.77, p=.68\right)$.

Table 1. Participants' target choices by gender

\begin{tabular}{|c|c|c|c|}
\hline Measure & no eyeglasses & eyeglasses & no difference \\
\hline \multicolumn{4}{|l|}{ Sexiness } \\
\hline Male & $12.7 \%$ & $18.2 \%$ & $69.1 \%$ \\
\hline Female & $17.9 \%$ & $26.8 \%$ & $55.4 \%$ \\
\hline \multicolumn{4}{|l|}{ Prettiness } \\
\hline Male & $49.1 \%$ & $23.6 \%$ & $27.3 \%$ \\
\hline Female & $60.7 \%$ & $17.9 \%$ & $21.4 \%$ \\
\hline \multicolumn{4}{|l|}{ Elegance } \\
\hline Male & $18.2 \%$ & $54.5 \%$ & $27.3 \%$ \\
\hline Female & $10.7 \%$ & $62.5 \%$ & $26.8 \%$ \\
\hline \multicolumn{4}{|c|}{ Good-looking } \\
\hline Male & $67.3 \%$ & $10.9 \%$ & $21.8 \%$ \\
\hline Female & $69.6 \%$ & $19.6 \%$ & $10.7 \%$ \\
\hline \multicolumn{4}{|l|}{ Youth } \\
\hline Male & $7.3 \%$ & $9.1 \%$ & $83.6 \%$ \\
\hline Female & $7.1 \%$ & $25.0 \%$ & $67.9 \%$ \\
\hline \multicolumn{4}{|c|}{ Selected by others } \\
\hline Male & $49.1 \%$ & $20.0 \%$ & $30.9 \%$ \\
\hline Female & $62.5 \%$ & $12.5 \%$ & $25.0 \%$ \\
\hline \multicolumn{4}{|c|}{ Selected for album } \\
\hline Male & $76.4 \%$ & $3.6 \%$ & $20.0 \%$ \\
\hline Female & $80.4 \%$ & $5.4 \%$ & $14.3 \%$ \\
\hline
\end{tabular}




\section{Discussion}

The results of our study indicate that a target's wearing of eyeglasses influences our judgment of physical attractiveness in different ways and that the negative effects of eyeglasses on perceived face bear on many dimensions of physical attractiveness. However, only elegance is positively evaluated when a target is wearing eyeglasses. This finding is consistent with previous research. For example, Saito (1978) reported that eyeglasses produce a higher estimation of perceived neatness. It appears that eyeglasses may give an aura of sophistication to wearers. In fact, some studies have indicated that wearing eyeglasses is associated with perceived higher conscientiousness and intelligence (Guéguen, 2015; Guéguen \& Martin, 2017; Okamura, 2018). Hence, it is assumed that elegance is highly estimated in the same way as neatness, conscientiousness and intelligence. Moreover, it is found that eyeglasses have no effect on judgments of sexiness and youth. As for sexiness, the result is in line with Bartolini et al. (1988), who reported no effect of eyeglasses on perceived sexiness. With respect to youth, the result confirmed that eyeglasses do not influence perceptions of the target's youth and suggested that the effect of eyeglasses on physical attractiveness does not depend on the target's youth.

This research has laid the groundwork for future study of the eyeglasses effect on physical attractiveness, having established that the effect depends on which dimension of physical attractiveness is being judged.

The study has some limitations that need to be addressed. First, we did not take into consideration whether participants wear eyeglasses. It was reported that people positively evaluate others who have similar physical characteristics and people who wear eyeglasses are likely to judge others who wear them more favorably (Mackinnon, Jordan, \& Wilson, 2011). On the basis of this finding, the possibility that eyeglasses wearers evaluate the female target more positively than no-eyeglasses wearers could be assessed by identifying whether participants ordinarily wear eyeglasses. Second, characteristics of eyeglasses (e.g., shape, material, color, and size) could be important factors for judgments of the face. In one example, a study demonstrated that signs associated with aging were the presence of heavier eyeglasses and eyeglasses with large lenses (Lewis, Medvedev, \& Seponski, 2011). In another example, a study showed that the shape of eyeglasses influences facial impressions (Okamura \& Ura, 2017). Third, only one female was used as a target in the study. Therefore, at this stage, it would be impossible to generalize the results to account for other female targets and other types of eyeglasses (or the combination of these elements). However, given previous research that showed an effect of eyeglasses on facial impressions of women, and were the results of this study to be confirmed in other targets, the study would be useful for women considering whether to wear eyeglasses in different situations.

\section{Acknowledgement}

The author received no financial support for the research. The author would like to thank the reviewers for their helpful comments and suggestions.

\section{References}

Bar, M., Neta, M., \& Linz, H. (2006). Very first impressions. Emotion, 6(2), 269-278. doi:10.1037/1528-3542.6.2.269

Bartolini, T., Kresge, J., McLennan, M., Windham, B., Buhr, T. A., \& Pryor, B. (1988). Perceptions of personal characteristics of men and women under three conditions of eyewear. Perceptual and Motor Skills, 67, 779-782. doi:10.2466/pms.1988.67.3.779

Brown, M. J., Henriquez, E., \& Groscup, J. (2008). The effects of eyeglasses and race on juror decisions involving a violent crime. American Journal of Forensic Psychology, 26(2), 25-43.

Faul, F., Erdfelder, E., Lang, A.G., \& Buchner, A. (2007). G*Power 3: a flexible statistical power analysis program for the social, behavioral, and biomedical sciences. Behavior Research Methods, 39, 175-191. doi:10.3758/BF03193146

Guéguen, N. (2015). Effect of wearing eyeglasses on judgment of socioprofessional group membership. Social Behavior and Personality, 43(4), 661-666. doi:10.2224/sbp.2015.43.4.661

Guéguen, N., \& Martin, A. (2017). Effect of Interviewer's Eyeglasses on Compliance with a Face-to-face Survey Request and Perception of the Interviewer. Field Methods, 29. 194-204. doi:10.1177/1525822X17713661

Guéguen, N., Stefan, J., \& Renault, Q. (2016). Judgments toward women wearing high heels: a forced-choice evaluation. Fashion and Textiles, 3:6. doi:10.1186/s40691-016-0058-9

Hasart, J. K., \& Hutchinson, K. L. (1993). The effects of eyeglasses on perceptions of interpersonal-attraction. Journal of Social Behavior and Personality, 8, 521-528.

Jellesma, F. C. (2013). Do glasses change children's perceptions? Effects of eyeglasses on peer- and selfperception. European Journal of Developmental Psychology, $\quad 10, \quad 449-460$. doi:10.1080/17405629.2012.700199

Kawana, Y. (2013). Female attraction interfered from appearance. The journal of the Psychological Institute, Rissho University, 11, 13-23.

Leder, H., Forster, M., \& Gerger, G. (2011). The glasses stereotype revisited: Effects of eyeglasses on perception, recognition, and impression of faces. Swiss Journal of Psychology, 70, 211-222. doi:10.1024/1421-0185/a000059

Lewis, D. C., Medvedev, K., \& Seponski, D. M. (2011). Awakening to the desires of older women: Deconstructing ageism within fashion magazines. Journal of Aging Studies, 25(2), 101-109. doi:10.1016/j.jaging.2010.08.016

Lo, C. H., Yang, C. Y., Lin, P. T., Hsieh, K. J., Liu, Y. C., \& Chiou, W. K. (2012). Are human faces more attractive with glasses? Journal of the Chinese Institute of Industrial Engineers, 29(2), 125-135. doi:10.1080/10170669.2012.662917

Lundberg, J. K., \& Sheehan, E. P. (1994). The effects of glasses and weight on perceptions of attractiveness and intelligence. Journal of Social Behavior and Personality, 9, 753-760.

Mackinnon, S. P., Jordan, C. H., \& Wilson, A. E. (2011) Birds of a feather sit together: Physical similarity predicts seating choice. Personality and Social Psychology Bulletin, 37, 879-892. doi:10.1177/0146167211402094

Miyazaki, Y., \& Kawahara, J. (2016). The sanitary-mask effect on perceived facial attractiveness. Japanese Psychological Research, 58, 261-272. doi:10.1111/jpr.12116

Mulhern, R., Fieldman, G., Hussey, T., Lévêque, J. L., \& Pineau, P. (2003). Do cosmetics enhance female 
Caucasian facial attractiveness? International Journal of Cosmetic

Science, 25, 199-205. doi:10.1046/j.1467-2494.2003.00188.x

Okamura, Y. (2018). The effect of the shape of eyeglasses on judgements toward wearers' occupations: Replication and extension of Guéguen (2015). Romanian Journal of Psychological Studies, 6(1), 17-22.

Okamura, Y., \& Ura, M. (2017). Facial impressions caused by shapes of faces and eyeglasses. Proceedings of the Human and Social Sciences at the Common Conference, 5(1), 1012. doi:10.18638/hassacc.2017.5.1.228

Saito, K. (1978). An experimental study of personality judgement: Effect of wearing glasses. Japanese Journal of Experimental Social Psychology, 17, 121-127. doi: 10.2130/jjesp.17.121

Swami, V., Stieger, S., Pietschnig, J., Voracek, M., Furnham, A., \& Tovée, M. J. (2012). The influence of facial piercings and observer personality on perceptions of physical attractiveness and intelligence. European
Psychologist, $\quad 17, \quad 213-221 . \quad$ doi: $\quad 10.1027 / 1016-$ 9040/a000080

Terry, R. L., \& Kroger, D. L. (1976). Effects of eye correctives on ratings of attractiveness. Perceptual and Motor Skills, 42, 562. doi: 10.2466/pms.1976.42.2.562

Thornton, G. R. (1943). The effect upon judgments of personality traits of varying a single factor in a photograph. Journal of Social Psychology, 18, 127-148. doi: 10.1080/00224545.1943.9921704

Willis, J. \& Todorov, A. (2006). First impressions: Making up your mind after a $100-\mathrm{ms}$ exposure to a face. Psychological Science, 17(7), 592-598. doi:10.1111/j.1467-9280.2006.01750.x

Yoo, J. W., \& Jin, Y. J. (2015). Reverse transfer effect of celebrity-product congruence on the celebrity's perceived credibility. Journal of Promotion Management, 21(6), 666-684. doi: 10.1080/10496491.2015.1055046 